\title{
Bioestimulante, biofertilizante e inoculação de sementes no crescimento e produtividade da soja
}

\section{Carlos Alderete Prieto ${ }^{1}$, Jimmy Walter Rasche Alvarez², Julio César Karajallo Figueredo', Simeón Aguayo Trinidad ${ }^{1}$}

\author{
${ }^{1}$ Escuela Superior de Enseñanza Cruce Itakyry, Universidad Nacional del Este, Itakyry, Paraguay.E-mail: \\ aldereteprieto@hotmail.com, krajallojc@ hotmail.com, aguayotrinidad@gmail.com \\ ${ }^{2}$ Facultad de Ciencias Agrarias-Universidad Nacional de Asunción, Asunción, Paraguay. E-mail: jwrasche@yahoo.com.ar
}

Recebido: 18/06/2016; Aceito: 30/03/2017

\section{RESUMO}

Com o objetivo de avaliar o efeito da aplicação de biostimulante (BES), de biofertilizante (BIO) e da inoculação (INO) de sementes de soja com Bradyrhizobium sobre o crescimento e a produtividade da soja foi realizada a pesquisa em Minga Porã, Paraguai, em um Rhodic Paleudult (Latossolo Vermelho). O delineamento experimental foi de blocos ao acaso num arranjo fatorial $3 \times 3 \times 3$, com 5 repetições. $O$ fator um foi a aplicação de bioestimulante - controle, $500 \mathrm{~mL}$ em $100 \mathrm{~kg}$ de semente e $500 \mathrm{~mL}$ no estágio R2 da soja. O fator dois foi a aplicação de biofertilizante - controle, 160 e $320 \mathrm{~L} \mathrm{ha}^{-1}$ no estágio V1 da soja, e o fator três foi a inoculação com Bradyrhizobium - controle, $200 \mathrm{~mL}$ e $400 \mathrm{~mL}$ em $100 \mathrm{~kg}$ de semente. Foi determinada a altura final de planta, massa de 1000 grãos e produtividade de grãos. A produtividade aumentou 6,78\% com a aplicação de biofertilizante na dose de $320 \mathrm{~L} \mathrm{ha}^{-1}$ em estágio V1. Existe interação do bioestimulante com o inoculante em altura de planta e produtividade de grãos. Quando aplicado $500 \mathrm{~mL}$ de bioestimulante no estágio R2 da soja com a maior dose de inoculante ( $400 \mathrm{~mL}$ por $100 \mathrm{~kg}$ de semente $\left.{ }^{-1}\right)$ há decréscimo da produtividade. Nem sempre a mistura de vários produtos resulta em aumento de produtividade.

Palavras-chave: Bradyrhizobium japonicum, Glycine max, adubação biológica auxina, citocinina, giberelina

\section{Biostimulate, biofertilization and seeds inoculation on growth and soybean yield}

\begin{abstract}
The objective was to evaluate the application of biostimulant (BES), biofertilizers (BIO) and inoculant (INO) with Bradyrhizobium growth and soybean yield, a research was conducted in Minga Pora, Paraguay, in a Ultisol (Latossolo Vermelho). The experimental design was randomized complete blocks in a factorial arrangement $3 \times 3 \times 3$, with five replications. Factor 1 was biostimulant in dose of control and $500 \mathrm{~mL}$ in $100 \mathrm{~kg}$ of seed, and 500 $\mathrm{mL}$ on soybean stage R2. Factor 2 was application of biofertilizers in control, 160 and $320 \mathrm{~L} \mathrm{ha}^{-1}$ in V1 stage of soybeans and factor 3 was inoculation with Bradyrhizobium in control, 200 and $400 \mathrm{~mL}$ per $100 \mathrm{~kg}$ of seed. Were determined final plant height, grain yield and weight of 1000 grains. The grain yield increased in $6.78 \%$ with biofertilizer application in the dose of $320 \mathrm{~L} \mathrm{ha}^{-1}$ in stage V1. There is interaction of the biostimulant with the inoculant at plant height and grain yield. When the highest dose of biostimulant tested $500 \mathrm{~mL}$ in the R2 stage of soybean with the highest inoculant dose $\left(400 \mathrm{~mL}\right.$ per $\left.100 \mathrm{~kg}_{\text {of seed }}{ }^{-1}\right)$ was applied, there was a decrease in grain yield. Mixing multiple products does not always result in increased productivity
\end{abstract}

Key words: Bradyrhizobium japonicum, Glycine max, biological fertilization, auxin, cytokinin, gibberellin 


\section{Introdução}

A soja [Glycine max (L.) Merrill] é originaria da China, seus grãos são ricos em proteína e óleo, produto que constitui importante fonte de alimentação animal e humana em escala mundial. O Paraguai é o sexto maior produtor e quarto maior exportador de soja no mundo, com uma área cultivada de 3.264 .480 milhões de hectares, apresentando na safra de 2014/2015 produção de 8.004.858 milhões de toneladas e produtividade média de $2.452 \mathrm{~kg} \mathrm{ha}^{-1}$ (INBIO, 2015).

Considerando a importância desta cultura no Paraguai, varias tecnologias são aplicadas tentando aumentar o seu rendimento, principalmente relacionadas ao uso de novos produtos, como a utilização de micronutrientes em diferentes formulações e combinações, biofertilizantes, bioestimulantes ou biorreguladores de crescimento, inoculantes, entre outros, procurando incrementar a produtividade das culturas. No entanto, pouco se conhece sobre o efeito real desses produtos na produtividade de grãos (FERREIRA et al., 2007; AGUAYO et al., 2015).

Entre os novos produtos oferecidos no mercado, os bioestimulantes tem tido boa aceitação pelos produtores. São substâncias sintéticas formadas pelo conjunto de reguladores vegetais ou também compostos de nutrientes, aminoácidos e outros produtos, que aplicados exógenamente, alcançam efeitos similares ao grupo de hormônios vegetais conhecidos como a citocinina, giberelina, auxina, ácido abscísico e etileno. Estas, em baixas concentrações inibem, promovem ou modificam processos morfológicos e fisiológicos dos vegetais. Os bioestimulantes têm sido recomendados para incrementar a produtividade da soja através da aplicação via foliar ou nas sementes. No entanto, os resultados em relação à aplicação de bioestimulantes na soja são contraditórios, tendo trabalhos que apresentam resultados positivos sobre o rendimento (MORTELE et al., 2008; BERTOLIN et al., 2010; CARVALHO et al., 2013) e alguns não (DARIO et al., 2005; ALBRECHT et al., 2010); não há estudos relacionados com os mesmos na zona produtora de soja no Paraguai.

Por outro lado, biofertilizantes ou fertilizantes biológicos baseados em fermentados microbianos enriquecidos vem sendo utilizados como estratégia para incrementar a produtividade, tanto em agricultura intensiva como extensiva. A fertilização biológica busca incorporar organismos benéficos ao solo para manter o equilíbrio na atividade microbiana, aumentando a fertilidade do solo e, inclusive diminuindo a incidência de pragas e doenças (MEDEIROS et al., 2003; MEDEIROS; LOPES, 2006). Embora até o momento os resultados encontrados em relação à eficiência da aplicação de fertilizantes biológicos não se apresentem contundentes, existe uma tendência de favorecimento da produtividade com o uso de biofertilizantes (VITTI et al., 2000; OLIVEIRA; SANTOS, 2011; MESQUITA et al., 2014).

A inoculação é amplamente recomendada na soja, para obter altos rendimentos considerando seu alto requerimento em nitrogênio (HUNGRÍA; ARAÚJO, 1999). Os inoculantes geralmente usados na cultura da soja são do gênero Bradyrhizobium; bactérias fixadoras de $\mathrm{N}_{2}$ atmosférico que através da ação simbiótica com as plantas formam estruturas especializadas na raiz denominadas nódulos onde ocorre o processo de fixação biológica (CHEN et al., 2000), convertendo assim o $\mathrm{N}_{2}$ atmosférico em amônio $\left(\mathrm{NH}_{4}{ }^{+}\right)$assimilável pelas plantas (HUNGRÍA et al., 2001).

Considerando a falta de informação local sobre o uso de produtos alternativos utilizados de forma massiva nos últimos anos na fertilização da soja, é importante realizar pesquisas que aportarão informações aos produtores de soja que utilizam estes produtos. $\mathrm{O}$ objetivo do trabalho foi avaliar o efeito da aplicação de bioestimulante, biofertilizante e da inoculação de sementes com Bradyrhizobium sobre o crescimento e a produtividade da soja.

\section{Material e Métodos}

O experimento foi realizado no município de Minga Porã, Departamento de Alto Paraná, Paraguai, nas coordenadas geográficas, 2451'18.7" S y 5452'52.6" W e altitude de $255 \mathrm{~m}$. O solo predominante da região é classificado como Rhodic Paleudult, de textura argilosa (LÓPEZ et al., 1995), equivalente ao Latossolo Vermelho (EMBRAPA, 2006). O clima da região é subtropical subúmido, com temperatura média anual de $22^{\circ} \mathrm{C}$ e precipitação média anual de $1750 \mathrm{~mm}$. (LÓPEZ et al., 1995).

O solo da área do experimento utilizado no sistema plantio direto a mais de 10 anos possuía trigo como cultura antecessora à soja. Antes da implantação do experimento foi extraída amostra de solo na camada 0$10 \mathrm{~cm}$ para a análise de textura e dos atributos químicos do solo. O solo apresentava inicialmente $480 \mathrm{~g} \mathrm{~kg}^{-1}$ de argila, pH em água de 5,3; matéria orgânica de 19,2 g $\mathrm{kg}^{-1}$ e saturação da CTC por bases de 62\%; 8,3 e $110 \mathrm{mg}$ $\mathrm{kg}^{-1}$ de fósforo e potássio, respectivamente. A adubação da soja com $\mathrm{P}$ e $\mathrm{K}$ foi realizada seguindo a recomendação de Cubilla et al. (2012), aplicando $250 \mathrm{~kg}$ ha $^{-1}$ do fertilizante $0-20-20$ na semeadura da soja, considerando o resultado de análise do solo.

Antes da semeadura da soja foi aplicado mecanicamente $1,28 \mathrm{~L} \mathrm{ha}^{-1}$ do principio ativo de glifosato $64 \% \mathrm{SL}$ adicionado a $0,5 \mathrm{~L} \mathrm{ha}^{-1}$ de óleo mineral parafínico $42,8 \%$ EC para o controle de plantas espontâneas. Foi utilizada a semente de soja SYN 1059 RR (V-TOP), de crescimento indeterminado e precoce. A semeadura foi realizada em meados de outubro de 
2014, em sistema de plantio direto sobre a palhada de trigo, com o espaçamento de $0,45 \mathrm{~cm}$ e 16 sementes por metro linear.

$\mathrm{O}$ delineamento experimental foi de blocos ao acaso com arranjo fatorial $3 \times 3 \times 3$, com 27 tratamentos e 5 repetições, totalizando 135 unidades experimentais, em uma área total de $7290 \mathrm{~m}^{2}$, onde foi avaliada o efeito principal e interações entre os fatores. Cada unidade experimental com medição de $10 \mathrm{~m} \mathrm{x} \mathrm{4,95} \mathrm{m} \mathrm{(49,5} \mathrm{m²)}$ e área útil por unidade experimental de $30,4 \mathrm{~m}^{2}$.

$\mathrm{O}$ primeiro fator foi a aplicação de bioestimulante (BES): a) Controle - $0 \mathrm{~mL}$ por $100 \mathrm{~kg}$ de semente, b) $500 \mathrm{~mL}$ por $100 \mathrm{~kg}$ de semente e c) $500 \mathrm{~mL} \mathrm{ha}^{-1}$ no estágio R2 da soja. O fator dois foi a aplicação de biofertilizante (BIO): a) controle - $0 \mathrm{~L} \mathrm{ha}^{-1}$, b) $160 \mathrm{~L} \mathrm{ha}^{-1}$ em estágio V1 e c) $320 \mathrm{~L} \mathrm{ha}^{-1} \mathrm{em} \mathrm{V1}$. O terceiro fator foi a aplicação de inoculante (INO): a) controle - $0 \mathrm{~mL}$ por $100 \mathrm{~kg}$ de semente, b) $200 \mathrm{~mL}$ por $100 \mathrm{~kg}$ de semente e c) $400 \mathrm{~mL}$ por $100 \mathrm{~kg}$ de semente ${ }^{-1}$. O bioestimulante apresentou concentração de $0,005 \%$ de ácido indolbutírico (auxina), 0,009\% de cinetina (citocinina) e $0,005 \%$ de ácido giberélico (giberelina).

O fertilizante biológico avaliado apresentou na sua concentração substâncias recalcitrantes, preparados biodinâmicos, pentoses e minerais. $\mathrm{O}$ fertilizante biológico estava composto por $89 \%$ de bactérias e $11 \%$ de fungos e leveduras na sua concentração. O mesmo foi obtido em tanque de fermentação biológica de 12.000 litros cumprindo com todos os processos de Compostagem Líquida Contínua $\left(\mathrm{CLC}^{\circledR}\right)$. O inoculante usado continha bactérias do género Bradyhrizobium das cepas: SEMIA 5019 (Bradyrhizobium elkanii) e SEMIA 587 (Bradyrhizobium elkanii) de concentração mínima de $5 \times 10^{9}$ células viáveis $\mathrm{mL}^{-1}$.

A aplicação de BES na semente foi realizada imediatamente antes da semeadura e da inoculação das sementes, diluído em água de acordo as especificações do fabricante. Para a aplicação do BES no estágio R2 foi utilizado um pulverizador de pressão constante $\left(\mathrm{CO}_{2}\right)$, com bico tipo cônico com volume de calda de $100 \mathrm{~L} \mathrm{ha}^{-1}$. O BIO foi aplicado com um pulverizador costal de capacidade de $5 \mathrm{~L}$, usando bico tipo defletor para aplicação de fertilizante biológico, em função do produto apresentar resíduos orgânicos.

Foi aplicado o micronutriente Co $1 \%$, Mo $6 \%$ via foliar, em dose de $200 \mathrm{~mL} \mathrm{ha}^{-1}$ dividido em duas aplicações, a primeira em estágio V2 e a segunda aplicação em V5, com calda de $100 \mathrm{~L} \mathrm{ha}^{-1}$ em cada aplicação. $\mathrm{O}$ controle de plantas espontâneas foi realizado com aplicação de $1,28 \mathrm{~L} \mathrm{ha}^{-1}$ do principio ativo de Glifosato $62 \%$ SL em pós-emergência aos 25 dias após a semeadura. Para o controle de pragas foram usados os seguintes princípios ativos, lufenurón 400 g
$\mathrm{L}^{-1}+$ benzoato de emamectina $100 \mathrm{~g} \mathrm{~L}^{-1} \mathrm{WG}$ e thiametoxam $141 \mathrm{~g} \mathrm{~L}^{-1}+$ lambdacihalothrin $106 \mathrm{~g} \mathrm{~L}^{-1}$ $\mathrm{SC}$, onde se realizaram seis aplicações, com intervalo de 20 dias nas três primeiras aplicações e a cada 10 dias nas aplicações restantes pelo ataque de Spodoptera sp e Helicoverpa sp e percevejo, principalmente Euschistus heros e Dichelops furcatus.

Para o controle de doenças, principalmente para controle da ferrugem da soja (Phakopsora pachyrhizi) foi aplicado azoxystrobin $200 \mathrm{~g} \mathrm{~L}^{-1}+$ cyproconazole 80 $\mathrm{g} \mathrm{L}^{-1} \mathrm{SC}$, com quatro aplicações. A primeira foi realizada aos 30 dias da semeadura, a segunda aplicação 17 dias depois da primeira, a terceira aplicação aos 16 dias depois e a última aplicação 13 dias depois da anterior; em todas as aplicações foi usado aderente mineral.

Foi determinada a altura de 10 plantas sequenciais por unidade experimental em centímetros com uma fita métrica, em estágio R8, considerando o comprimento desde a base da planta (colo) até o ápice da mesma. Para determinar a produtividade da soja foram colhidas nove fileiras com 7,5 metros por fileira $\left(30,4 \mathrm{~m}^{2}\right)$; as plantas foram trilhadas com uma trilhadora rotativa engatada à um trator. A massa de 1000 grãos de soja e a produtividade foram mensuradas em balança de precisão, ajustado o grau de umidade a $13 \% \mathrm{e}$, posteriormente os resultados foram expressos em kg ha-1 para produtividade e g para massa de 1000 grãos.

Para a análise estatística foi realizada análise de variância (ANOVA) e havendo diferenças significativas, foi aplicado o teste de Tukey a 5\% de probabilidade, para comparação de medias entre tratamentos.

\section{Resultados e Discussão}

Houve interação entre a aplicação de bioestimulante e inoculação de sementes, além do efeito isolado de aplicação de inoculante para as avaliações de altura de plantas e biofertilizante para produtividade de grãos (Tabela 1). No que se refere à massa de 1000 grãos de soja, não se observou influencia da aplicação de bioestimulante, biofertilizante ou inoculante e mesmo interação entre estes sobre a massa de 1000 grãos (Tabela 1).

Considerando que o coeficiente de variação foi inferior a $12 \%$ para a altura de planta de soja e $16 \%$ para o rendimento de grãos, pode-se argumentar que o experimento foi bem manejado e que os dados são confiáveis (CARVALHO et al., 2003).

A aplicação de biofertilizante não influenciou na altura de planta de soja no estágio R8, variando a altura entre 97,3 a 97,6 cm (Tabela 2). 
Tabela 1. ANOVA - Altura de planta, produtividade de grãos e massa de 1000 grãos, avaliadas em diferentes doses de bioestimulante (BES), biofertilizante (BIO) e inoculante (INO). Minga Porã, 2014.

\begin{tabular}{|c|c|c|c|}
\hline Fatores & $\begin{array}{l}\text { Altura de planta } \\
(\mathrm{cm})\end{array}$ & $\begin{array}{l}\text { Produtividade grãos } \\
\left(\mathrm{kg} \mathrm{ha}^{-1}\right)\end{array}$ & $\begin{array}{l}\text { Massa de } 1000 \\
\text { grãos }(\mathrm{g})\end{array}$ \\
\hline Bioestimulante (BES) & $18,52^{\mathrm{ns}}$ & $132999,21^{\mathrm{ns}}$ & $27,14^{\mathrm{ns}}$ \\
\hline Biofertilizante (BIO) & $1,05^{\mathrm{ns}}$ & $689362,06^{* *}$ & $5,81^{\mathrm{ns}}$ \\
\hline Inoculante (INO) & $49,98^{* * *}$ & $42926,99^{\mathrm{ns}}$ & $20,03^{\text {ns }}$ \\
\hline Int. BES x BIO & 11,12 ns & $178803,48^{\mathrm{ns}}$ & $12,56^{\mathrm{ns}}$ \\
\hline Int. BES x INO & $95,84^{* *}$ & $856817,44^{* *}$ & $6,52^{\mathrm{ns}}$ \\
\hline Int. BIO x INO & $16,89^{\text {ns }}$ & $50969,22^{\text {ns }}$ & 29,45 ns \\
\hline Int. BES x BIO x INO & $7,56^{\mathrm{ns}}$ & $163021,19^{\mathrm{ns}}$ & $6,34^{\mathrm{ns}}$ \\
\hline Coeficiente de Variação (\%) & 3,25 & 13,12 & 4,80 \\
\hline
\end{tabular}

ns: Não significativo pelo teste $\mathrm{F}(\mathrm{P}>0,05) ; * *$ Significativo $(\mathrm{P}<0,01)$ de probabilidade.

Tabela 2. Altura de planta de soja no estádio R8 por efeito da aplicação de biofertilizante. Minga Porã, 2014.

\begin{tabular}{llc}
\hline Tratamentos & & Altura de planta $(\mathrm{cm})$ \\
\hline & Controle $-0 \mathrm{~L} \mathrm{ha}^{-1}$ & M $97,6 \mathrm{a}$ \\
Biofertilizante & $160 \mathrm{~L} \mathrm{ha}^{-1}$ em estágio V1 & $97,4 \mathrm{a}$ \\
& $320 \mathrm{~L} \mathrm{ha}^{-1}$ em estágio V1 & $97,3 \mathrm{a}$ \\
\hline $\mathrm{CV}(\%)$ & & 16,38
\end{tabular}

${ }^{\mathrm{M}}$ Médias seguidas de mesma letra minúscula não diferem entre si pelo teste de Tukey $5 \%$ de probabilidade.

$\mathrm{Na}$ interação entre a aplicação do bioestimulante e inoculante (Tabela 3), observou-se que quando não foi aplicado o inoculante, houve aumento da altura de planta no estádio R2 comparado ao controle, com aumento de $3 \%$, passando de $96,9 \mathrm{~cm}$ a $99,9 \mathrm{~cm}$. A aplicação de $200 \mathrm{~mL}$ de Inoculante + bioestimulante em $100 \mathrm{~kg}$ de semente induziu a diminuição da altura de planta $(5,5 \%)$ comparado ao controle com $98,6 \mathrm{~cm}$. Quando aplicando $400 \mathrm{~mL}$ em $100 \mathrm{~kg}$ de semente de Inoculante + bioestimulante, houve aumento de altura de planta no R2 de 5,5\% e 3,6\% no R8. Aplicação de doses acima da recomendada pelos fabricantes de alguns reguladores vegetais como o ácido indolbutírico podem propiciar distúrbio fisiológico nas plantas ou tão somente não causar efeitos benéficos (CÂMARA, 1989). O desnível hormonal ocasionado pela aplicação de bioestimulantes via exógena pode levar a distúrbios metabólicos, os quais potencialmente geram radicais livres (ALBRECHT et al., 2010).

Ono et al. (2007), Mortele et al. (2008) e Bertolín et al. (2010) não observaram efeito na altura de plantas de soja quando aplicado bioestimulantes com os mesmos princípios ativos utilizados no presente experimento, embora tais autores não tenham estudado a interação deste com inoculante. Carvalho et al. (2013) constataram que a aplicação de doses de bioestimulante de $0,25 \mathrm{~L} \mathrm{ha}^{-1}$ apresentou menor altura de planta do que quando aplicadas doses de 0,75 ou $1,00 \mathrm{~L} \mathrm{ha}^{-1}$. Ferreira et al. (2007) ao avaliarem o efeito da aplicação do mesmo bioestimulante utilizado no presente experimento, associado ao tratamento de sementes de milho constataram que a incorporação de bioestimulante à semente de milho reduziu a germinação e vigor do milho, no entanto, promoveu maior desenvolvimento das raízes das plântulas.

No que se refere à aplicação de inoculante, observou-se que quando não aplicado bioestimulante, a dose de $200 \mathrm{~mL}$ em $100 \mathrm{~kg}$ de semente ${ }^{-1}$ foi a que apresentou maior altura de planta $(98,6 \mathrm{~cm}) \mathrm{em}$ comparação à aplicação da dose de $400 \mathrm{~mL}$ em $100 \mathrm{~kg}$ de semente ${ }^{-1}$. Quando aplicado $500 \mathrm{~mL}$ de bioestimulante em $100 \mathrm{~kg}$ de semente ${ }^{-1}$ não houve efeito da dose de inoculante sobre a altura de planta, no entanto ao se aplicar a mesma dose de biorregulador, mas no estádio R2 da soja o tratamento com $200 \mathrm{~mL}$ de inoculante apresentou a menor altura de planta $(94,2$ cm) (Tabela 3). A massa de 1000 grãos de soja não foi influenciada pela aplicação de bioestimulante, biofertilizante e inoculante (Tabela 4).

Esperava-se maior altura de planta com a aplicação de maiores doses de inoculante, pois o suprimento de nitrogênio para a planta permitiria maior possibilidade de crescimento desta, quando comparado à planta não inoculada.

Campos (1999) estudando o efeito da inoculação de sementes de soja não observou efeito da inoculação de diferentes doses de Bradyrhizobium na cultura da soja, em relação à altura de planta quando cultivada em plantio direto. Sotelo et al. (2010) avaliando a nodulação de plantas de soja verificaram que as mesmas são afetadas pela inoculação do cultivo anterior, todavia não observaram efeito da inoculação sobre a altura de planta quando estas foram inoculadas ou não. 
Tabla 3. Interação entre o bioestimulante e inoculante na altura de plantas da soja no estágio R8. Minga Porã, 2014.

\begin{tabular}{lccc}
\hline \multirow{2}{*}{ Bioestimulante } & \multicolumn{3}{c}{ Inoculação de sementes } \\
\cline { 2 - 4 } & Controle- $0 \mathrm{~mL}$ & $200 \mathrm{~mL}$ por $100 \mathrm{~kg} \mathrm{de} \mathrm{semente}^{-1}$ & $400 \mathrm{~mL} \mathrm{por} \mathrm{100kg} \mathrm{de} \mathrm{semente}^{-1}$ \\
\hline & M 96,9 bAB & Altura de planta (cm) & $94,8 \mathrm{bB}$ \\
Controle - 0 mL & $98,1 \mathrm{abA}$ & $98,6 \mathrm{aA}$ & $98,3 \mathrm{aA}$ \\
$500 \mathrm{~mL}$ por100 kg de semente & $99,9 \mathrm{aA}$ & $94,0 \mathrm{abA}$ & $100,0 \mathrm{aA}$ \\
\hline
\end{tabular}

${ }^{\mathrm{M}}$ Médias seguidas de mesma letra minúscula na coluna e maiúsculas linha não diferem entre si pelo teste de Tukey 5\% de probabilidade.

Tabela 4. Massa de 1000 grãos, avaliadas em função da aplicação de bioestimulante (BC), Biofertilizante (BIO) e Inoculante (INO). Minga Porã, 2014.

\begin{tabular}{|c|c|c|}
\hline Tratame & & Massa de 1000 grãos $(\mathrm{cm})$ \\
\hline \multirow{3}{*}{ Bioestimulante } & $0 \mathrm{~mL}$ & ${ }^{\mathrm{M}_{1} 13,6 \mathrm{a}}$ \\
\hline & $500 \mathrm{~mL} 100 \mathrm{~kg}$ de semente ${ }^{-1}$ & $115,2 \mathrm{a}$ \\
\hline & 500 mL no estágio $\mathrm{R} 2$ & 115,2 a \\
\hline \multirow{3}{*}{ Biofertilizante } & $0 \mathrm{~L} \mathrm{ha}^{-1}$ & $113,6 \mathrm{a}$ \\
\hline & $160 \mathrm{~L} \mathrm{ha}^{-1}$ em estágio V1 & $112,0 \mathrm{a}$ \\
\hline & $320 \mathrm{~L} \mathrm{ha}^{-1}$ em estágio V1 & 113,6 a \\
\hline \multirow{3}{*}{ Inoculante } & $0 \mathrm{~mL}$ & $113,6 \mathrm{a}$ \\
\hline & $200 \mathrm{~mL}$ em $100 \mathrm{~kg}$ de semente ${ }^{-1}$ & 113,6 a \\
\hline & $400 \mathrm{~mL}$ em $100 \mathrm{~kg}$ de semente ${ }^{-1}$ & 113,6 a \\
\hline
\end{tabular}

${ }^{\mathrm{M} M e ́ d i a s ~ s e g u i d a s ~ d e ~ m e s m a ~ l e t r a ~ n a ̃ o ~ d i f e r e m ~ e n t r e ~ s i ~ p e l o ~ t e s t e ~ d e ~ T u k e y ~ 5 \% ~ d e ~ p r o b a b i l i d a d e . ~}$

Estes resultados concordam com os de Bellini et al. (2013) que ao aplicarem biofertilizante via solo na cultura da soja, não observaram aumento na massa de 100 grãos pela aplicação de diferentes doses de biofertilizante na soja. Por outro lado, Carvalho et al. (2013) ao avaliarem a aplicação de biofertilizante na cultura da soja constataram aumento da massa de 1000 grãos quando aplicado altas doses de bioestimulante em aplicação foliar na cultura da soja.

A cultura da soja apresentou resposta positiva à aplicação de biofertilizante na produtividade de grãos (Tabela 5) onde a aplicação de $320 \mathrm{~L} \mathrm{ha}^{-1}$ no estágio V1 da soja permitiu aumento de 6,78\% (171 $\left.\mathrm{kg} \mathrm{ha}^{-1}\right)$ comparado à testemunha. A aplicação de biofertilizante na dose recomendada (160 $\left.\mathrm{L} \mathrm{ha}^{-1}\right)$ não afetou a produtividade. Estes resultados discordam dos resultados encontrados por Oliveira e Santos, (2011) que não constataram aumento na produtividade de soja pelo efeito da aplicação do biofertilizante. Possivelmente a resposta da aplicação de biofertilizante no presente experimento é devido ao déficit hídrico na etapa de R5. Teoricamente, estes biofertilizantes permitem a melhora do crescimento radicular por diminuir a densidade do solo. Em virtude de melhor estrutura do solo e atividade microbiana as raízes podem ter absorvido água em maior profundidade que nas parcelas sem aplicação de biofertilizante.

Também se contradiz ao exposto por Santos e Akiba (1996) que alertam sobre possível estresse fisiológico quando biofertilizante é aplicado em concentrações muito elevadas, principalmente quando realizada via foliar pode possivelmente porque induz ao desvio metabólico para produção de substâncias de defesa na planta, retardando seu crescimento, floração ou frutificação.

De forma similar ao que ocorreu com a altura de planta, houve interação entre a aplicação de bioestimulante e a aplicação de inoculante para produtividade de grãos (Tabela 6).

Quando não houve aplicação de inoculante observou-se menor rendimento da soja ao se aplicar a $500 \mathrm{~mL}$ do bioestimulante em $100 \mathrm{~kg}$ de semente ${ }^{-1}$, em comparação a aplicação $500 \mathrm{~mL}$ no estágio R2. Ao se usar $200 \mathrm{~mL}$ do inoculante em $100 \mathrm{~kg}$ de semente ${ }^{-1}$, a aplicação de bioestimulante não afetou o rendimento. A aplicação de $400 \mathrm{~mL}$ de inoculante em $100 \mathrm{~kg}$ de semente $+500 \mathrm{~mL}$ de bioestimulante no $\mathrm{R} 2$ provocaram menor rendimento de grãos.

Ao contrario do que ocorreu no presente experimento, Bertolin et al. (2010) constataram aumento do rendimento de grãos pela aplicação de bioestimulante, aplicado tanto via semente como via foliar. Carvalho et al., (2013) constataram aumento do rendimento de grãos na cultura da soja quando aplicado dose de $0,5 \mathrm{~L} \mathrm{ha}^{-1}$ do mesmo bioestimulante utilizado no presente experimento e realizado em três aplicações foliares na cultura da soja. Num experimento similar, Mortele et al. (2008) avaliando a cultura da soja com 
mesmas doses e bioestimulante, aplicados em dois estádios de desenvolvimento da cultura (V5 e R3) observaram aumento de produtividade de grãos no primeiro ano. A melhor resposta foi obtida com a aplicação de $211 \mathrm{~mL} \mathrm{ha}^{-1}$ de biorregulador via foliar no estádio R3, associado ao tratamento de sementes (500 $\mathrm{mL} 100 \mathrm{~kg}^{-1}$ de sementes). No segundo ano não houve efeito da aplicação do bioestimulante.

Tabela 5. Produtividade de grãos de soja no estádio R8 por efeito da aplicação de biofertilizante. Minga Porã, 2014.

\begin{tabular}{lrr}
\hline Tratamento & & Produtividade grãos (kg ha $^{-1}$ ) \\
\hline \multirow{2}{*}{ Biofertilizante } & $0 \mathrm{~L} \mathrm{ha}^{-1}$ & $\mathrm{M} 2.521 \mathrm{~b}$ \\
& $160 \mathrm{~L} \mathrm{ha}^{-1}$ em estágio V1 & $2.451 \mathrm{~b}$ \\
\hline $\mathrm{CV}(\%)$ & $320 \mathrm{~L} \mathrm{ha}^{-1}$ em estágio V1 & $2.692 \mathrm{a}$ \\
\hline
\end{tabular}

${ }^{\mathrm{M}}$ Médias seguidas de mesma letra minúscula não diferem entre si pelo teste de Tukey $5 \%$ de probabilidade.

Tabela 6. Interação entre o bioestimulante e inoculante na produtividade da soja. Minga Porã, 2014.

\begin{tabular}{|c|c|c|c|}
\hline \multirow{3}{*}{ Bioestimulante } & \multicolumn{3}{|c|}{ Inoculação de sementes } \\
\hline & Controle - $0 \mathrm{~mL}$ & $200 \mathrm{~mL} / 100 \mathrm{~kg} \mathrm{semente}{ }^{-}$ & $400 \mathrm{~mL} / 100 \mathrm{~kg}$ de semente ${ }^{-1}$ \\
\hline & \multicolumn{3}{|c|}{ Produtividade da soja $\left(\mathrm{kg} \mathrm{ha}^{-1}\right)$} \\
\hline Controle $-0 \mathrm{~mL}$ & $\mathrm{M}_{2.558 \mathrm{abA}}$ & $2.597 \mathrm{aA}$ & $2.602 \mathrm{aA}$ \\
\hline $500 \mathrm{~mL} 100 \mathrm{~kg}$ de semente ${ }^{-1}$ & $2.373 \mathrm{bB}$ & $2.384 \mathrm{aB}$ & $2.719 \mathrm{aA}$ \\
\hline $500 \mathrm{~mL}$ no estágio R2 da soja & $2.840 \mathrm{aA}$ & $2.632 \mathrm{aA}$ & $2.288 \mathrm{bB}$ \\
\hline
\end{tabular}

${ }^{\mathrm{M}}$ Médias seguidas de mesma letra minúscula na coluna e maiúsculas linha não diferem entre si pelo teste de Tukey $5 \%$ de probabilidade.

Ao se considerar a aplicação de inoculante sobre o rendimento de grãos da soja, observa-se que ao omitir a aplicação de bioestimulante a aplicação de inoculante não influenciou na produtividade da soja (Tabela 6). Quando aplicado $500 \mathrm{~mL}$ do biorregulador em $100 \mathrm{~kg}$ de semente ${ }^{-1}$ de soja ocorreu aumento do rendimento da soja com aplicação de $400 \mathrm{~mL}$ por $100 \mathrm{~kg}$ de semente ${ }^{-1}$. Ao contrário do que ocorreu com a aplicação de bioestimulante na semente de soja, a aplicação de bioestimulante no estádio R2 causou diminuição do rendimento da soja ao se aumentar a dose de inoculante (Tabela 6). Esses dados diferem dos trabalhos de Hungría et al., (2001) onde mencionam que a inoculação anual, mesmo em áreas com histórico de larga data de aplicação de inoculantes como a área do experimento resulta em aumento da produtividade entre 4 a 9\%. Ferraris e Couretot (2012) em quatro anos de avaliação constataram aumento entre $0,6 \%$ e $8 \%$ na produtividade de grãos pela inoculação da soja com Bradyrhizobium. Benintende et al. (2010) avaliando dois experimentos com inoculante na cultura da soja, realizados em solos que não tinham histórico de semeadura de soja nos últimos 10 anos anteriores a instalação dos experimentos, constataram aumento significativo na produtividade de grãos de soja nestes lugares.

Meghvansi e Mahna (2009) e Campos (1999) observaram aumento da nodulação pela aplicação de Bradyrhizobium, sem aumento de produtividade de soja com a inoculação, afirmando que não é necessário inocular a soja em campos com mais de 5 anos semeado com soja de plantio direto, pois o ambiente favorece o desenvolvimento das bactérias Bradyrhizobium no solo, diminuindo assim o efeito da inoculação.

De acordo aos resultados a aplicação de bioestimulante no estádio reprodutivo da soja exerce efeito negativo na soja quando inoculadas com Bradyrhizobium (400 mL por $100 \mathrm{~kg}$ de semente ${ }^{-1}$ ). Portanto deve se ter cautela ao misturar vários produtos em diferentes estádios fenológicos da cultura, pois nem sempre os resultados são positivos.

\section{Conclusões}

O biofertilizante aplicado em doses de $320 \mathrm{~L} \mathrm{ha}^{-1}$, em estágio V1, propiciou aumento na produtividade de grãos de soja.

Existe interação do bioestimulante com o inoculante em altura de planta e produtividade de grãos. Quando aplicado $500 \mathrm{~mL}$ de bioestimulante no estágio R2 da soja juntamente com maior dose de inoculante $(400 \mathrm{~mL}$ por $100 \mathrm{~kg}$ de semente $^{-1}$ ) ha decréscimo da produtividade.

\section{Referências Bibliográficas}

AGUAYO B, C. A.; RASCHE A, J. W. Fertilización foliar con boro en el cultivo de la soja, Revista Investigación Agraria, San Lorenzo-Py, v.17, n. 2, p. 129-137, 2015. Disponível 
http://www.agr.una.py/revista/index.php/ria/article/view/283 Acesso em: 5 de junho de 2016.

ALBRECHT, L. P.; BRACCINI, A. L.; SCAPIN, C. A.; AVILA, M. R.; A. L. P.; BARBOSA, M. C. Qualidade das sementes de soja produzidas sob manejo com biorregulador. Revista Brasileira de Sementes, Londrina-PR, v. 32, n. 4; p. 39-48. 2010. Disponível em: http://www.scielo.br/pdf/rbs/v32n4/05.pdf. Acesso em: 3 de maio de 2016.

BELLINI, G; SCHMIDT FILHO, E; MORESKI, H. M. Influência da aplicação de um fertilizante biológico sobre alguns atributos físicos e químicos do solo. Revista em Agronegócio e Meio Ambiente, Maringá-PR, v. 6, n. 2, p. 325-336. 2013. Disponível em: http://periodicos.unicesumar.edu.br/index.php/rama/article/vie w/2345. Acesso em: 13 de fevereiro de 2016.

BENINTENDE, S.; UHRICH, W.; HERRERA, M.; GANGGE, F.; STERREN, M.; BENINTENDE, M. Comparación entre coinoculación con Bradyrhizobium japonicum y Azospirillum brasilense e inoculación simple con Bradyrhizobium japonicum en la nodulación, crecimiento y acumulación de $\mathrm{N}$ en el cultivo de soja Agriscientia, Córdoba-Ar, v. 26, n. 2, p. 71-77. 2010. Disponível em: www.scielo.org.ar/scielo.php?script=sci_arttext\&pid=S1668298X2010000200002 Acesso em: 3 de maio de 2016.

BERTOLIN, D. C.; SÁ, M. E; ARF, O.; FURLANI JUNIOR, E.; COLOMBO A. S.; CARVALHO F. L. B. M. Aumento da produtividade de soja com a aplicação de bioestimulantes. Bragantia, Campinas-SP, v. 69, n. 2, p.339-347, 2010. Disponível em: http://www.scielo.br/pdf/brag/v69n2/11.pdf. Acesso em: 12 de fevereiro de 2016.

CÂMARA, F. L. A. Efeitos do substrato e da imersão em IBA, sobre o enraizamento de propágulos de mandioquinhasalsa. Horticultura Brasileira, Brasília-DF, v. 7, n. 1, p. 44, 1989. Disponível em: http://www.scielo.br/scielo.php?script=sci_arttext\&pid=S0102 -05362000000100012. Acesso em: 3 de abril de 2016.

ONO, E. O.; CAMPOS, M. F.; LIMA, G. P. P.; RODRIGUES, J. D. Desenvolvimento de plantas de soja em resposta aos reguladores vegetais. Revista Brasileira de Biociências, Porto Alegre-RS, v. 5, n. S2, p. 9-11, 2007. Disponível em: http://www.ufrgs.br/seerbio/ojs/index.php/rbb/article/view/47/ 49. Acesso em: 5 de maio de 2016.

CAMPOS, B. C. Dose de inoculante turfoso para soja em plantio direto. Ciência Rural, Santa Maria-RS, v. 29, n. 3, p. 423-426, $1999 . \quad$ Disponível em: http://www.scielo.br/scielo.php?script=sci_arttext\&pid=S0103 -84781999000300007. Acesso em: 14 de maio de 2016.

CARVALHO, C. G. P.; FARIAS, C. A. A.; TOLEDO, J. F. F.; ALMEIDA, L. A.; KIIHL, R. A. S.; OLIVEIRA, M. F.; HIROMOTO, D. M.; TAKEDA, C. Proposta de classificação dos coeficientes de variação em relação à produtividade e altura da planta de soja. Pesquisa Agropecuária Brasileira, Brasília-DF, v. 38, n. 2, p.187-193, 2003. Disponível em: http://www.scielo.br/pdf/pab/v38n2/v38n2a04.pdf. Acesso em: 10 de agosto de 2015 .

CARVAlHO, J. C.; VIECELlI, C. A.; ALMEIDA D. K. Produtividade e desenvolvimento da cultura da soja pelo uso de regulador vegetal. Acta Iguazu, Cascavel-PR, v. 2, n 1, p. 50-60, 2013. Disponível em: http://erevista.unioeste.br/index.php/actaiguazu/article/view/8166. Acesso em: 12 de agosto de 2015.

CHEN, L. S., FIGUEIREDO, A., PEDROSA, F. O., HUNGRIA, M. Genetic characterization of soybean rhizobia in Paraguay. Applied and Environmental Microbiology, Bethesda-USA, v. 66, n. 11, p. 5099-5103. 2000. Disponível em: http://www.ncbi.nlm.nih.gov/pmc/articles/PMC92426/. Acesso em: 8 de maio de 2016.

CUBILLA A, M. M; WENDLING, A.; ELTZ, F. L. F; AMADO, J. C.; MIELNICZUK. Recomendaciones de fertilización para Soja, Trigo, Maíz y Girasol bajo el Sistema de Siembra Directa en el Paraguay. Asunción-Py: Artemac S.A., 2012. 88 p. Disponível em: http://capeco.org.py/wp-content/uploads/2015/06/librofinal_recomendaciones-de-fertilizacion-paraguay_2012.pdf. Acesso em: 20 de março de 2016.

DARIO, G. J. A; MARTIN, T. N; DOURADO NETTO, D; MANFRON, P. A; BONNECARRERE, A. G.; CRESPO, P. E. N. Influência do uso de fitorregulador no crescimento da soja. Revista da FZVA. Uruguaiana-RS, v. 12, n. 1, p. 63-70. $2005 . \quad$ Disponível em: http://revistaseletronicas.pucrs.br/ojs/index.php/fzva/article/do wnload/2303/1796. Acesso em: 15 de agosto de 2015.

EMBRAPA. EMPRESA BRASILEIRA DE PESQUISA AGROPECUÁRIA. Sistema Brasileiro de Classificação de Solos Centro Nacional de Pesquisa de Solos. 2 ed. Rio de Janeiro-RJ: Embrapa Solos, 2006. 306 p.

FERRARIS, G.; COURETOT, L. Contribución de diferentes prácticas de manejo a la obtención de rendimientos potenciales en soja. Efectos sobre la nodulación, el rendimiento y su interacción con prácticas de manejo. Pergamino-Ar: INTA, 2012. 7 p. (Documento técnico 227).

FERREIRA, L. A; OLIVEIRA, J. A.; VON PINHO, E. V. R.; QUEIROZ, D. L. Bioestimulante e fertilizante associados ao tratamento de sementes de milho. Revista Brasileira de Sementes, Londrina-PR, v. 29, n. 2, p. 80-89, 2007. Disponível em: http://www.scielo.br/scielo.php?script=sci_arttext\&pid=S0101 $-31222007000200011 \& \operatorname{lng}=e n \& n r m=i s o$. Aceso em $12 \mathrm{de}$ junho de 2015.

HUNGRÍA, M., CAMPO, R. J., MENDES, C. L. Fixação biológica do nitrogênio na cultura da soja. Londrina-PR: Embrapa Soja, 2001. 48p. (Circular Técnica 35). Disponível em:

https://www.infoteca.cnptia.embrapa.br/bitstream/doc/459673/ 1/circTec35.pdf. Acesso em: 4 de maio de 2016.

HUNGRÍA, M.; ARAÚJO, F. F. Nodulação e rendimento de soja co-inoculada com Bacillus subtilis e Bradyrhizobiumj aponicum/B. elkanii. Pesquisa Agropecuária Brasileira, Brasilia-DF, v. 34, n. 9, p. 1633-1643. 1999. Disponível em: http://www.scielo.br/pdf/pab/v34n9/7615.pdf. Acesso em: 6 de abril de 2016.

PEKHOLTZ, F. (Org) Superficie sembrada, producción y productividad del cultivo de soja. Campaña 2014/15. Asunción-Py: Instituto de Biotecnología Agrícola. 2015. 26 p. (Boletín técnico). Disponível em: http://www.inbio.org.py/uploads/Estimacion_de_superficie_se 
mbrada,_produccion_y_productividad_del_cultivo_de_soja,_c ampana_2014-2015.pdf Acesso em 8 de março de 2016.

LÓPEZ, O.; GONZALEZ, E; LLAMAS, P.A; MOLINAS, A. S; FRANCO, E. S., GARCÍA, S.; RÍOS, E. O. Estudio de reconocimiento de suelos, capacidad de uso de la tierra y propuesta de ordenamiento territorial preliminar de la Región Oriental del Paraguay. Asunción-Py: Banco Mundial, DMA, 1995. 246 p. Disponível em: http://www.geologiadelparaguay.com/Estudio-de-

Reconocimiento-de-Suelos-Regi\%C3\%B3n-Oriental-

Paraguay.pdf. Acesso em: 5 de junho de 2016.

MEDEIROS B, M.; WANDERLEY, P. A; WANDERLEY, M. J. A. Biofertilizantes líquidos. Revista Biotecnologia, Ciência \& Desenvolvimento, Brasilia-DF, v. 31, n. 2, p. 3844, $2003 . \quad$ Disponível em: http://www.biotecnologia.com.br/revista/bio31/biofertilizante. pdf. Acesso em: 5 de janeiro de 2016.

MEDEIROS, M. B.; LOPES, J. S. Biofertilizantes líquidos e sustentabilidade agrícola. Bahia Agrícola, Salvador-BA, v. 7, n. 3, p. 24-26, 2006. Disponível em: http://www.seagri.ba.gov.br/sites/default/files/comunicacao05 _v7n3.pdf. Acesso em: 4 de maio de 2016.

MEGHVANSI, M. K.; MAHNA, S. K. Evaluating the Symbiotic Potential of Glomus intraradices and Bradyrhizobium japonicum in Vertisol with Two Soybean Cultivars. American-Eurasian Journal of Agronomy, Dubai-UAE, v. 2, n. 1, p. 21-25, 2009. Disponível em: http://www.idosi.org/aeja/2(1)09/5.pdf. Acesso em: 5 de março de 2016.

MESQUITA, A. C; GAMA S, D. R; YURI, J. E; NASCIMENTO S, E; DOURADO F, T. S. Utilização de biofertilizante na produção de duas cultivares de melão. Revista SODEBRAS, Curitiba-PR, v. 9, n. 107, p. 52-55, 2014. Disponível em: https://www.alice.cnptia.embrapa.br/alice/bitstream/doc/9984 98/1/jONY2014.pdf. Acesso em: 3 de maio de 2016.
MORTELE L.M.; SANTOS R.F.; BRACCINI, A.L.; SCAPIM, C.A.; BARBOSA, M.C. Efeito da aplicação de biorregulador no desempenho agronômico e produtividade da soja. Acta Scientiarum Agronomy, Maringá-PR, v. 30, p. 701-709. 2008. Disponível em: http://periodicos.uem.br/ojs/index.php/ActaSciAgron/article/vi ew/5971. Acesso em: 12 de abril de 2016.

OLIVEIRA, R. C; SANTOS, D. V. Adubação foliar na estimulação de nodulação e produtividade da soja. Cultivando o Saber. Cascavel-PR, v. 4, n. 1, p. 140-146, 2011.

SANTOS, A. C.; AKIBA, F. Biofertilizantes líquidos: uso correto na agricultura alternativa. Rio de Janeiro-RJ: Seropédica - Imprensa Universitária/UFRRJ, 1996. 35p.

SOTELO, C. E.; LECONTE, M. C.; IGLESIAS, M. C. Efecto de la inoculación al cultivo antecesor sobre la nodulación de la soja, en suelos de desmonte. Agrotecnia, Corrientes-Ar, v. 20, n. 1, p. 13-17. 2010. Disponível em: http://baunne.unne.edu.ar/revista_agrotecnia/pdfs/AG_20_10_ 03_Sotelo.pdf Acesso em: 8 de maio de 2016.

VITTI, G. C., CARDOSO, E. J. B. N., PINTO, T. L. F. Avaliação da decomposição da palha, estado nutricional, produtividade e qualidade da cana colhida sem queima a partir da aplicação do produto Microgeo. Piracicaba-SP: Escola Superior de Agricultura Luís de Queiroz-USP, 2000. $64 \mathrm{p}$. 